\title{
O dramático como potencializador do desenvolvimento e da educação cultural
}

\author{
Delfim Paulo Ribeiro \\ Investigador Integrado, Research in Education and Community Intervention (RECI), Portugal.
}

\begin{abstract}
Resumo
Este trabalho aborda a importância do drama no desenvolvimento e na educação. $\mathrm{O}$ trabalho assume que a riqueza psicopedagógica do drama encontra-se na mútua dependência da ação e da emoção. O dramatizar, para além de incentivar os participantes a comunicarem os seus raciocínios e sentimentos, permite aos indivíduos explorarem a forma como outras pessoas se sentiriam ou agiriam em situações semelhantes. Deste modo, não se confinando exclusivamente ao âmbito pessoal, as dramatizações ampliam a extensão das experiências e dos conhecimentos; desafiando a compreensão mais óbvia e unívoca da cultura vigente. O trabalho não deixa igualmente de referir que, para além da vertente psicopedagógica e desenvolvimental, o drama na educação abrange modelos pedagógicos mais centrados na promoção da literacia artística, tendo em vista a formação de indivíduos capazes de compreender a cultura dramática em que se inserem e de valorizar o património teatral.
\end{abstract}

Palavras-chave: jogo dramático, desenvolvimento cognitivo, empatia, educação cultural

Estudos da área da psicopedagogia têm evidenciado que o brincar simbólico e a representação de papéis estão intimamente relacionados com o desenvolvimento humano. Estes processos, inerentes à natureza do drama e do teatro, têm vindo a ser implementados em diversos contextos educativos.

Através do brincar dramático a criança cria e explora mundos imaginários. Experimenta ações e consequências. Imita os adultos. Cria personagens. Exprime desejos e medos. A partir de certa altura, o brincar espontâneo passa a estar de tal modo presente na vida das crianças que começa a ser facilmente identificado. Quando encorajado pela disponibilização dos locais e equipamentos apropriados, o brincar dramático revela-se uma manifestação natural e saudável do desenvolvimento.

Com o decorrer do tempo, o brincar espontâneo passa a evidenciar, através do jogo dramático, a aceitação de regras partilhadas. O saber esperar a sua vez, o respeito pelo outro e a predisposição para a cooperação são ingredientes que necessitam de estar bem firmados no jogo dramático. Porém, de forma diferente dos jogos de azar e da atividade física, o jogo dramático incluí normalmente a exploração lúdica e imaginária de problemáticas inerentes ao relacionamento humano.

\section{Brincar dramático, jogo e teatro}

Alguns autores têm elaborado analogias entre o drama e o jogo. Watkins (1983, p.37) perspetiva as atividades dramáticas à luz das teorias de Huizinga (1992), considerando que o brincar dramático se apresenta como a atividade lúdica através da qual os participantes "desempenham papéis de forma semelhante ao comportamento social”. Porém, diferentemente do brincar dramático espontâneo, o jogo dramático implica a existência de algumas regras predefinidas - ainda que flexíveis - sendo muitas vezes orientado para determinados objetivos educativos (Ribeiro, 2005). Podemos facilmente aperceber-nos destas características ao analisarmos os livros com compilações de atividades dramáticas, onde, habitualmente, os jogos são classificados pela sua intencionalidade educativa e adequação a determinada faixa etária (e.g. Meighan, 2011; Theodorov, 2010).

De forma distinta do brincar e do jogo dramático, o teatro implica tradicionalmente a elaboração de um produto; uma peça que é ensaiada e apresentada a um público. Sobretudo, devemos entender que o teatro é uma arte multifacetada, abrangendo diversas tendências estéticas e culturais. A arte teatral tende a revelar, de forma condensada e intencional, a complexidade da vida e os seus dilemas mais profundos. No teatro, as personagens dramáticas inter-relacionam-se num mundo ficcionado, através do qual o público se emociona e reflete sobre a natureza humana e as problemáticas sociais (Cooper, 2013).

\section{Enquadramentos educativos do dramático}

A designação drama na educação refere o conjunto de atividades e metodologias que utilizam a dramatização para alcançar objetivos educativos. O drama na educação diferencia-se, por isso, do brincar dramático espontâneo no seu alcance, intenção e estrutura, visto ser implementado tendo em conta uma determinada intencionalidade pedagógica.

De uma forma geral, a escassez de adereços e cenários, a dispensa do uso de textos e a improvisação podem ser aceites como as principais características do que é usualmente entendido como drama na educação. No entanto, mesmo no âmbito pedagógico, devemos compreender que a nítida distinção entre o drama como processo educativo e o drama como produto artístico tem vindo a esbater-se (Anderson, 2012; Barker, 2010). Cooper (2013) afirma que o drama na educação é atualmente perspetivado como uma disciplina que abrange um vasto leque de práticas relacionadas com o brincar dramático, com jogos promotores do desenvolvimento e com a aprendizagem de técnicas e convenções teatrais. Esta abrangência de objetivos induz necessariamente a procura do equilíbrio metodológico que permita perspetivar o drama e o teatro como experiências educativas complementares; admitindo, simultaneamente, a natural predisposição das crianças 
para o brincar dramático e a progressiva aquisição das técnicas e convenções teatrais que potencializam os benefícios educativos do seu envolvimento com a arte.

Devemos entender que, normalmente, o teatro para adultos pressupõe uma capacidade de compreensão que ultrapassa a maturidade cognitiva e emocional das crianças. Por outro lado, a desmesurada atenção dada ao espetáculo como mero entretenimento torna difícil encontrar, em certas propostas teatrais, qualquer valor educativo. Segundo Cooper (2013) é importante percebermos que o teatro na educação diz respeito às perspetivas teatrais que exploram e demonstram uma preocupação específica com os valores e os processos educativos. Neste caso, fortificando a literacia artística, o teatro na educação assume a necessidade de aproximar o drama escolar às metodologias mais direcionadas para o produto, englobando a aprendizagem técnica e a apreciação artística informada e crítica. Ultrapassadas as clivagens que existiam entre os radicais da pedagogia exclusivamente centrada no processo e os defensores da pedagogia centrada no produto, devemos assumir atualmente a necessidade de promover uma visão abrangente e tolerante sobre o drama na educação. É neste sentido que Walkinshaw (2004, p. 184) afirma que o drama na educação “ necessita sobretudo de ser visto como polimorfo, fecundo, didático, dialético, pedagógico e divertido; o que exige o reconhecimento tanto das semelhanças como das diferenças entre as diversas metodologias”.

\section{Drama, desenvolvimento e consciência}

Brian Way, um dos pedagogos de maior destaque na área do drama na educaçãoassume que a dramatização é um dos indutores mais privilegiados do desenvolvimento emocional e social das crianças. A dramatização é apresentada por Way $(1967$, p.3) como um processo que apela “à individualidade dos indivíduos”, à "singularidade de cada essência humana”; revelando-se uma espécie de instigador do desenvolvimento psicológico que conduz ao crescimento emocional e ao autoconhecimento.

Ao longo do desenvolvimento, através dos exercícios promotores da concentração e do aprimoramento dos sentidos, as crianças vão progredindo para um maior envolvimento emocional e intelectual com as dramatizações. Inicialmente, as dramatizações são mantidas no âmbito da esfera pessoal, tendo exclusivamente por referência o mundo interno das próprias crianças que dramatizam. Posteriormente, acedendo à consciencialização dos outros e reconhecendo as suas circunstâncias particulares, as personagens passam a ser elaboradas levando em linha de conta as características específicas do mundo interno de quem é dramatizado. Este processo de criação e representação de personagens, como resultado da projeção imaginária da própria pessoa - quer nas circunstâncias que dizem respeito à vida dos outros quer procurando "ser" os outros nas suas próprias circunstâncias - permite aprofundar a experiência da singularidade pessoal e da singularidade do outro. É o pôr-se à prova em situações diversificadas, através do relacionamento dinâmico do próprio indivíduo com as personagens que vai criando, que permite que os sujeitos desenvolvam os seus recursos pessoais e a sua personalidade, num processo de crescimento pessoal simultaneamente emocional e intelectual. Assim, a representação dramática, incentiva as dinâmicas cognitivas que permitem às crianças e aos adolescentes desenvolverem, inicialmente, a nível intuitivo e subconsciente e, posteriormente, de forma mais consciente, o conhecimento de si-próprias, assim como a empatia e a compaixão.

\section{A natureza da aprendizagem dramática}

Referimos que a dramatização coloca em jogo uma multiplicidade de estruturas e dinâmicas relacionadas com o funcionamento mental. $\mathrm{O}$ envolvimento das pessoas com o "faz de conta" e com a representação nunca deixa de desencadear processos de transformação do pensamento. Quando os indivíduos se envolvem com a dramatização mental ou com atos dramáticos externos, transformam objetos, ideias, outras pessoas, elas próprias e o mundo que as rodeia (Watkins,1983; Wilkinson, 2000). Tal como temos vindo a afirmar, através do ato de representar os sujeitos envolvem-se cognitivamente com outras pessoas, procuram compreende-las e, fazendo isto, também se compreendem melhor a si-próprios. Sobretudo, segundo Courtney (1990, p.21) a representação do outro ajuda a ultrapassar a intolerância e o estereótipo, "permitindo ultrapassar ideias fixas e pré-concebidas”.

No enquadramento psicopedagógico, a aprendizagem dramática não é direcionada para os conteúdos ou assuntos das dramatizações. Não são os temas das improvisações (família, viagem, etc.) que interessam como objetivos ou conteúdos da aprendizagem, mas sim os processos mentais inerentes à dinâmica da própria dramatização. O que realmente importa é a forma como o pensamento e a ação se conciliam e padronizam (Anderson, 2012; Walkinshaw, 2004). No âmbito psicopedagógico deve entender-se que a aprendizagem dramática é alcançada pelo relacionamento entre premissas e assunções mais ou menos subconscientes e a sua consciencialização simbólica e metafórica colocada em jogo através da ação imediata. Em última instância, para a conceção psicopedagógica, o que importa são as perspetivas existenciais que evocam respostas profundas. Courtney (1990, p.144) ilustra bem esta ideia quando afirma que o drama de Hamlet não serve para conhecermos o enredo e as contingências específicas da peça, mas essencialmente para podermos “olhar para nós próprios e para toda a humanidade”.

\section{Arte dramática e educação}

Se olharmos à nossa volta percebemos que vivemos submersos num mundo dramático, carregado de rituais, personagens e ficções que nos são oferecidos como referência e moldam a nossa vida. Ainda que possamos não ir muitas vezes ao teatro, não deixamos de ser influenciados pelas inúmeras mensagens veiculadas pela televisão e pelo cinema. Histórias dramatizadas de todo o tipo permeiam a nossa vida. Segundo Willis (1990, p. 49) 
para além de nos permitirem analisar criticamente a nossa cultura, "as ficções dramatizadas oferecem-nos muitas das metáforas que culturalmente dão sentido à nossa existência”.

Tendo em conta a ubiquidade e importância da criação dramática na nossa vida, Anderson (2012) assume que o drama na educação deve ser usado para tornar os estudantes mais conscientes e informados sobre as estruturas dramáticas que permeiam a vida. Segundo este ponto de vista, o drama na educação apresenta-se como um indutor cultural através do qual os sujeitos podem aceder aos conhecimentos e às experiências que lhes permitem desenvolver-se como "utilizadores e observadores informados da arte dramática” (Hornbrook,1998a, p.13). Esta metodologia prende-se com o desenvolvimento das habilidades necessárias para a criação e fruição da arte dramática, alcançada, por exemplo, através de processos que incorporam a criação de enredos e personagens, a sua apresentação teatral e o desenvolvimento de uma postura crítica e informada por parte do público (Nicholson, 2009; Schonmann, 2005). A análise, adaptação, criação e produção de narrativas dramáticas, sob a forma de texto ou outro tipo de notação, apresenta-se central neste tipo de metodologia. A narrativa dramática, simples ou complexa na sua estrutura, é o que realmente permite a comunicação entre os atores e o público. Nas aulas de drama os estudantes podem utilizar peças publicadas (que interpretam e produzem em texto dramático) ou elaborarem, eles próprios, a notação sob a forma de notas, esquemas e guiões mais ou menos pormenorizados. No entanto, quer se trate do registo esquemático das ideias dos estudantes ou da base literária do teatro (escrita dramatúrgica), a notação, enquanto não for encenada, deve ser somente considerada como um guião, isto é, como um registo escrito e não dramático. Para se completar na sua maior abrangência educativa, o processo implica necessariamente o colocar em cena, envolvendo todos os elementos de produção de um espetáculo, desde a encenação e o trabalho de ator, até à logística de divulgação e gestão. É esta abrangência de procedimentos com objetivos pedagógicos que abre o drama na educação à criação e fruição artística, ajudando a criar cidadãos mais informados, participativos e críticos perante as problemáticas socioculturais que os rodeiam.

\section{Referências}

Anderson, M. (2012). Masterclass in drama education; transforming, teaching and learning. London: Continuum International Publishing Group.

Barker, C. (2010). Theatre games: a new approach to drama training. London: Mehuen Drama.

Cooper, C. (2013). The imagination in actin: TIE and its relationship to drama in education today. En A. Jackson, C. Vine (Ed.), Learning through theatre: The changing face of theatre in education ( ${ }^{\text {th }}$ Edit.) (pp.41-59). New York: Routledge.
Courtney, R. (1990). Drama and intelligence: A cognitive theory. Montreal: McGill-Queen's University Press.

Hornbrook, D. (1998a). Drama and education. En D. Hornbrook (Ed.), On the subject of drama (pp.6-17). London: Routledge.

Hornbrook, D. (1998b). Crafting dramas. En D. Hornbrook, (Ed.), On the subject of drama (pp.51-67). London: Routledge.

Huizinga, J. (1992). Homo ludens: o jogo como elemento da cultura. São Paulo: Perspectiva. (Originalmente publicado em 1938).

Meighan, R. (2011). Drama start, drama activities, plays and monologues for young children. Dublin: JemBooks.

Nicholson, H. (2009). Theatre and Education. Hampshire: Palgrave Macmillan.

Ribeiro, D. (2005). Movimento e drama criativo na animação de grupos: cinco questões para uma prática fundamentada. Animarte. Ano XIII, no 55, pp. I-VIII.

Schonmann, S. (2005). "Master" Versus "Servant": Contradictions in drama and theatre education. The Journal os Aesthetic Education. Vol. 39, Num. 4, winter 2005, 31-39.

Slade, P. (1995). Child Play: It's importance for human development. London: Jessica Kingsley.

Theodorov, M. (2010). Games, ideas and activities for primary drama ( $2^{\text {th }}$ Edit.). Harlow: Pearson Education

Wagner, B. (1979). Dorothy Heathcote: drama as a learning medium. London: Hutchinson \& Co.

Walkinshaw, A. (2004). Integrating drama with primary and junior education: the ongoing debate. New York: The Edwin Mellen Press.

Watkins, B. (1983). Drama as Game. En J. Norman (Ed.), Issues in Educational Drama (pp.35-48). London: Farmer Press.

Way, B. (1967). Development Through Drama. London: Longman.

Wilkinson, J. (2000). Literacy, Education and Arts Partnership: a community-system programme integrating the arts across the curriculum. Research in Drama Education , Vol. 5, N. 2, 175-197.

Willis, P. (1990) Common Culture: Symbolic Work at Play in the Everyday Cultures of the Young. Milton Keynes: Open University Press. 